\title{
Atopic Dermatitis - Knowledge and Attitude of Primary Health Care Providers, Majmaah, Saudi Arabia
}

\author{
Rasheed Khalid Barradah ${ }^{1}$ \\ ${ }^{1}$ Department of Dermatology, College of Medicine, Majmaah University, Al Majmaah 11952, Saudi Arabia.
}

\section{ABSTRACT}

\section{BACKGROUND}

Atopic dermatitis (AD) is common in Saudi Arabia. Level of primary health care providers' (PHCPs) knowledge about the disease is inadequate. We wanted to determine the knowledge and attitude of primary health care providers (PHCPs) in Majmaah, Saudi Arabia, toward atopic dermatitis (AD).

\section{METHODS}

This cross-sectional study was conducted in Majmaah, Saudi Arabia, from August to October 2020. The data was collected from eight primary healthcare centres in the city by a pre-tested questionnaire. The data was analysed using SPSS 26.0. Pearsonchi-square / Fisher Exact test were applied to observe associations between qualitative variables. A P-value of $<0.05$ was considered as statistically significant.

\section{RESULTS}

The data was collected from 23 PHCPs. The qualification obtained by most of the PHCPs (78.3 \%) was Bachelor of Medicine \& Bachelor of Surgery (MBBS), $17.4 \%$ were diploma holders and only one had master's degree. The average AD score out of 8 items was $5.95+1.18$. The minimum and maximum scores were 3 and 8 . Converting the scores to percentages, the participants who had good knowledge about AD were 17 (73.91\%). Five (21.74\%) had average knowledge and only one (4.35\%) had poor knowledge.

\section{CONCLUSIONS}

The level of atopic dermatitis knowledge of PHCPs in Majmaah, Saudi Arabia, was found to be adequate, whereas the attitude was observed to be negative. Focus-group discussions, tailored sessions, or continuous medical education programs can be conducted to discuss the management guidelines on this condition with the PHCPs.

\section{KEY WORDS}

Atopic Dermatitis, Primary Healthcare Centres, Knowledge, Attitude, Saudi Arabia
Corresponding Author: Dr. Rasheed Khalid, Barradah, Department of Dermatology, College of Medicine, Majmaah University, Al Majmaah 11952, Saudi Arabia.

E-mail: r.baradah@mu.edu.sa

DOI: $10.14260 /$ jemds/2021/566

How to Cite This Article:

Barradah RK. Atopic dermatitis knowledge and attitude of primary health care providers (PHCPS), Majmaah, Saudi Arabia. J Evolution Med Dent Sci 2021;10(33):2773-2777, DOI: 10.14260/jemds/2021/566

Submission 15-03-2021,

Peer Review 15-06-2021,

Acceptance 21-06-2021,

Published 16-08-2021.

Copyright (C) 2021 Rasheed Khalid Barradah. This is an open access article distributed under Creative Commons Attribution License [Attribution 4.0 International (CC BY 4.0)] 


\section{BACKGROUND}

Atopic dermatitis, also called allergic dermatitis or atopic eczema, is an inflammatory skin disease with a chronically relapsing course. The disease is characterized by episodes of intense pruritus, lichenification, severely dry skin, and susceptibility to cutaneous infections. ${ }^{1-3}$ The disease may have periods of complete remission, particularly in adolescence, and may then recur in early adult life. Most patients improve; this can occur at any age. AD affects almost one-fifth of all individuals during their lifetime; however, the prevalence differs in different countries. ${ }^{4,5}$ It was stated that the $\mathrm{AD}$ prevalence rate is rising, and it affects $15 \%-30 \%$ and $2 \%$ $10 \%$ of children and adults, respectively, worldwide. 6,7

The disease is common in children but can occur at any age. ${ }^{8,9}$ Atopic dermatitis runs a chronic course and tends to flare periodically. It may be accompanied by asthma or hay fever. $\mathrm{AD}$ is often associated with an elevation in serum immunoglobulin E and family history of atopy, that describes a group of diseases including eczema, allergic rhinitis, and asthma. In adults, $\mathrm{AD}$ affects different parts of the body compared to manifestations in children.10,11 Management of $\mathrm{AD}$ consists of relieving symptoms and increase time between flare-ups. Use of emollients at regular basis is recommended. The pharmacologic treatment of the disease is primarily topical corticosteroids once daily. A maintenance dose of topical corticosteroids may help reducing relapse in patients with recurrent moderate to severe forms of the disease. Although some experiences showed possible link between AD treatment and some malignancies like lymphoma, this was not demonstrated with strong evidence. Some forms of complementary and alternative medicines such as traditional chinese medicine (TCM) and Homeopathy are used to treat AD, but their effect is still a controversy. ${ }^{12}$

Atopic Dermatitis is common in Saudi Arabia, Alqhtan JM reported that the disease was present in $40.5 \%$ of Najran University students in south-western Saudi Arabia. ${ }^{13}$ The prevalence of $\mathrm{AD}$ among children in Jazan, Saudi Arabia showed considerable difference in presentation from those reported at local and regional levels. The results showed that population living in plain areas were more susceptible to $A D$ than those living in other areas. ${ }^{14}$

Knowledge of PHC practitioners about dermatological conditions including $\mathrm{AD}$ was inadequate as reported by Alkatheri AA et al. who found that $94 \%$ of PHCP in Jeddah, Saudi Arabia had inadequate knowledge. ${ }^{15}$ A study conducted by Al-Zahrani et al. in Abha, Saudi Arabia intending to evaluate the knowledge Attitude and Practice of PHC physicians found that most of the respondents had low education related to dermatology. The study also showed that most of the primary healthcare physicians lacked basic knowledge of common dermatological disorders including atopic dermatitis. They also reported lack of guidelines for management of dermatological disorders. ${ }^{16}$ A study conducted in Sudair Area of Saudi Arabia reported lack in knowledge and practice among physicians regarding management of Atopic Dermatitis. The study demonstrated that the practice of physicians was affected by age. ${ }^{17}$

This inadequate knowledge was also reported in England, Wales, and North India. 16,18,19 To improve physicians' experiences, five key consistent, evidence-based messages were stated by Cowdell F et al. - "eczema is more than just dry skin, eczema does not just go away, moisturizers are for every day, steroid creams are okay when you need them, and you know your child's eczema best". ${ }^{20}$ We wanted to determine Atopic Dermatitis knowledge and attitude of Primary Health Care Providers in Majmaah, Saudi Arabia.

\section{METHODS}

This cross-sectional study was conducted in Majmaah, Saudi Arabia from August - October 2020. The data was collected from eight primary healthcare centres (PHCs), Alfiha, Alfaisilia, Alyarmook, Almatar, Al Majmaah, Albusera and Harma in Majmaah city. A total of 23 primary healthcare physicians (PHCPs) were working in all PHCs. Complete enumeration sampling technique was used to collect the data using direct investigation method. The research was approved by the Central Institutional Review Board, Ministry of Health, Kingdom of Saudi Arabia vide reference no 2019 - 0174E. A self-prepared questionnaire was used to collect the data. The submitted questionnaire comprised of four sections. Section A contained questions related to the demographic and educational information of the PHCPs, Section B and C comprised of knowledge and attitude questions, respectively. The Internal Consistency Reliability (ICR) through Cronbach Alpha was evaluated for each section separately.

Section B (knowledge) comprised of 8 multiple choice questions (MCQ's), each MCQ had only one correct answer with responses coded as $0=$ wrong, $1=$ don't know, and $2=$ correct. The scores ranged from 0 - 8; a higher score indicated a higher level of knowledge. In the second step, the quantitative knowledge score was categorized into percentage. A score of $<50 \%$ was categorized as having poor knowledge, 50 - $75 \%$ was regarded as average knowledge and $>75 \%$ was considered as having adequate knowledge. The Cronbach Alpha for Knowledge section was 0.641. Section C comprised of 14 questions that assessed PHCP's attitude towards AD. All the questions were measured on a five - point Likert scale. The attitude of the PHCPs was further classified as positive and negative based on the mean scores. Values at or above the mean were classified as having a positive attitude, and values below the mean were referred to as having a negative attitude. The Cronbach Alpha for attitude section was 0.613 .

\section{Sample Size}

The entire kingdom of Saudi Arabia (KSA) is divided into Health Clusters. Majmaah is a town near Riyadh with a population of around 60,000. It has 8 primary healthcare centres and 23 PHCPs are working there. We have used the complete enumeration sampling technique to collect the data from all PHCP's working in 8 PHC's.

\section{Statistical Analysis}

The data was entered and analysed using SPSS 26.0 (IBM Corp., New York, NY, USA). Mean \pm S. D had been reported for quantitative variables like age. Frequencies and percentages were given for qualitative variables. One-sample t-test was applied to evaluate the participants mean AD knowledge score with the threshold value of $50 \%$. One-sample chi-square test 
was also applied to compare the distribution of positive and negative attitude. Pearson-chi-square / Fisher Exact test were applied to observe associations between qualitative variables (knowledge, attitude, and practice with demographic variables). A P - value of $<0.05$ was considered as statistically significant.

\section{RESULTS}

The data was collected from 23 PHCPs with the mean age of $43.57 \pm 7.23$ years. All the PHCPs were non-Saudi and most were males $12(52.2 \%)$ as compared to the females 11 (47.8 $\%)$. Almost $60 \%$ of the PHCPs belonged to the age-group of 35 - 44 years, followed by $>50$ years. 6 (26.1\%) and only 3 (13 $\%)$ PHCPs were between the age of 45 and 49 years. Five PHCPs (21.7 \%) were working at Almatar PHC, 4 (17.4\%) each at Alfiha and Harma PHCs, 3 (13\%) each at Alfaisilia and Alyarmook PHC's and 2 (8.7 \%) each at Al Majmaah and Albusera PHCs. Of all the qualification obtained by most of the PHCPs, 18 (78.3 \%) had Bachelor of Medicine \& Bachelor of Surgery (MBBS), 4 (17.4\%) were Diploma holders and only one had master's degree. More than $90 \%$ of the PHCPs were general practitioners and only $2(8.7 \%)$ were residents. Interms of experience, most of them $12(52.2 \%)$ had between 7 and 10 years, followed by $>10$ years who were $10(43.5 \%)$ and only one had experience between 4 and 6 years. Results are presented in Table 1.

\begin{tabular}{|ccc|}
\hline \multicolumn{2}{|c|}{ Demographic Characteristics } & N (\%) \\
Gender & Male & $12(52.2)$ \\
& Female & $11(47.8)$ \\
Age (years) & $35-39$ & $7(30.4)$ \\
& $40-44$ & $7(30.4)$ \\
Qualification & 45 and more & $9(39.1)$ \\
& Masters & $1(46.0)$ \\
Specialty & MBBS & $18(54.0)$ \\
& Diploma & $4(17.4)$ \\
Experience (years) & General Practitioner & $21(91.3)$ \\
& Resident & $2(8.70)$ \\
& 4 - 10 & $13(56.5)$ \\
& $>10$ & $10(43.5)$ \\
& Alfiha & $4(17.4)$ \\
PHC & Alfaisilia & $3(13.0)$ \\
& Alyarmook & $3(13.0)$ \\
& Almatar & $5(21.7)$ \\
& Al Majmaah & $2(8.70)$ \\
\hline Table 1. Demographic Characteristics of PHCP $(\mathbf{N}=\mathbf{2 3})$ \\
\hline
\end{tabular}

\begin{tabular}{|ccc|}
\hline Item & Stem & $\begin{array}{c}\text { N (\%) } \\
\text { Correct } \\
\text { Answers }\end{array}$ \\
1 & Familiarity with diagnostic criteria for atopic dermatitis & $21(91.3)$ \\
2 & Knowledge of the aetiology of AD & $21(91.3)$ \\
3 & Associated factors with AD & $19(82.6)$ \\
4 & The most important symptom of AD & $22(95.7)$ \\
5 & The common sites of AD in children (0-5 years old) & $18(78.3)$ \\
6 & The common sites of AD in adults (25 years old and above) & $8(34.8)$ \\
7 & Clinical presentation of AD & $9(39.1)$ \\
8 & Prevention of recurrence of AD after proper treatment? & $19(82.6)$ \\
\hline \multicolumn{3}{|c|}{ Table 2. Atopic Dermatitis - Knowledge of the PHCP's $\mathbf{~} \mathbf{N}=\mathbf{2 3})$} \\
\hline \multicolumn{3}{|c}{}
\end{tabular}

The average AD score out of 8 items was $5.95+1.18$, the minimum and maximum scores were 3 and 8 . Converting the scores to percentages, the participants had fair knowledge J Evolution Med Dent Sci / eISSN - 2278-4802, pISSN - 2278-4748 / Vol. 10 / Issue 33 / Aug. 16, 2021
(74.45 \%) about AD. The result of a one-sample t-test confirmed that the participants had overall significant fair knowledge about AD ( $\mathrm{P}<0.001)$. This was achieved by comparing the $\mathrm{AD}$ percentage score $(74.45 \%)$ with the threshold value of $50 \%$. The percentages of correct answers for each item are presented in Table 2. Overall, the majority of participants had adequate knowledge 17 (73.91\%) about $\mathrm{AD}$, $5(21.74 \%)$ had fair knowledge and only $4.35 \%$ had poor knowledge about AD (Figure 1).

Results presented in Table 3 shows that no significant association was observed between gender and knowledge of the participants about $\mathrm{AD}(\mathrm{P}=0.544)$, participant's knowledge about $\mathrm{AD}$ was also not significantly associated with working PHC $(P=0.327)$, age $(P=0.073)$, qualification $(P=0.961)$, specialty $(\mathrm{P}=0.679)$, and experience in specialty $(\mathrm{P}=0.231)$.

\begin{tabular}{|c|c|c|c|c|c|}
\hline \multirow{2}{*}{\multicolumn{2}{|c|}{ Socio-Demographics }} & \multicolumn{3}{|c|}{ Knowledge Score } & \multirow{2}{*}{$\begin{array}{l}\text { Significance } \\
\text { P-Value }\end{array}$} \\
\hline & & \multirow{2}{*}{$\begin{array}{c}\text { Poor } \\
1(100 \%)\end{array}$} & \multirow{2}{*}{$\begin{array}{c}\text { Fair } \\
2(40.0 \%)\end{array}$} & \multirow{2}{*}{$\begin{array}{l}\text { Adequate } \\
9(52.9 \%)\end{array}$} & \\
\hline \multirow{2}{*}{ Gender } & Female & & & & \multirow{2}{*}{0.544} \\
\hline & Male & $0(0.0 \%) 3$ & $3(60.0 \%)$ & $8(47.1 \%)$ & \\
\hline \multirow{7}{*}{ Working PHC } & Alfiha & $0(0.0 \%)$ & $0(0.0 \%)$ & $4(23.5 \%)$ & \multirow{7}{*}{0.327} \\
\hline & Alfaisilia & $0(0.0 \%)$ & $2(40 \%)$ & $1(5.9 \%)$ & \\
\hline & Alyarmook & $1(100 \%)$ & $0(0.0 \%)$ & $2(11.8 \%)$ & \\
\hline & Almatar & $0(0.0 \%)$ & $1(20 \%)$ & $4(23.5 \%)$ & \\
\hline & Al Majmaah & $0(0.0 \%)$ & $0(0.0 \%)$ & $2(11.8 \%)$ & \\
\hline & Albusera & $0(0.0 \%)$ & $1(20 \%)$ & $1(5.9 \%)$ & \\
\hline & Hamra & $0(0.0 \%)$ & $1(20 \%)$ & $3(17.6)$ & \\
\hline \multirow{2}{*}{ Age (years) } & $35-39$ & $0(0.0 \%)$ & $3(60 \%)$ & $4(23.5 \%)$ & \multirow{2}{*}{0.073} \\
\hline & 40 and more & $1(100 \%) 2$ & $2(40.0 \%)$ & $13(76.5 \%)$ & \\
\hline \multirow{2}{*}{ Qualification } & Masters & $0(0.0 \%)$ & $0(0.0 \%)$ & $1(5.9 \%)$ & \multirow{2}{*}{0.961} \\
\hline & Diploma, MBBS & $1(100 \%)$ & $5(100 \%)$ & $16(94.1 \%)$ & \\
\hline \multirow[t]{2}{*}{ Specialty } & $\begin{array}{c}\text { General } \\
\text { Practitioner }\end{array}$ & $1(100 \%)$ & $5(100 \%)$ & $15(88.2 \%)$ & \multirow[t]{2}{*}{0.679} \\
\hline & Resident & $0(0.0 \%)$ & $0(0.0 \%)$ & $2(11.8 \%)$ & \\
\hline \multirow{2}{*}{$\begin{array}{l}\text { Experience } \\
\text { Specialty }\end{array}$} & $4-6$ years & $0(0.0 \%)$ & $1(20 \%)$ & $0(0.0 \%)$ & \multirow[b]{2}{*}{0.231} \\
\hline & 7 years and more & $\begin{array}{c}1(100.0 \\
\%)\end{array}$ & $4(80 \%)$ & $\begin{array}{c}17(100.0 \\
\%)\end{array}$ & \\
\hline & - Rosocicit & $\begin{array}{l}\text { n between } \\
\text { hic Charac }\end{array}$ & AD Kno & $\begin{array}{l}\text { wledge and } \\
\text { s }(N=23)\end{array}$ & \\
\hline
\end{tabular}

\begin{tabular}{|c|c|c|c|c|}
\hline \multirow{2}{*}{\multicolumn{2}{|c|}{ Socio-demographics }} & \multicolumn{2}{|c|}{ Attitude Score } & \multirow{4}{*}{\begin{tabular}{|c|} 
Significance \\
P - Value \\
0.554
\end{tabular}} \\
\hline & & Negative & Positive & \\
\hline \multirow{2}{*}{ Gender } & Female & $9(56.3 \%)$ & $3(42.9 \%)$ & \\
\hline & Male & $7(43.8 \%)$ & $4(57.1 \%)$ & \\
\hline \multirow{7}{*}{ Working PHC } & Afhiha & $4(25.0 \%)$ & $0(0.0 \%)$ & \multirow{7}{*}{0.193} \\
\hline & Alfasailia & $1(6.30 \%)$ & $2(28.6 \%)$ & \\
\hline & Alyarmook & $1(6.30 \%)$ & $2(28.6 \%)$ & \\
\hline & Almatar & $3(18.8 \%)$ & $2(28.6 \%)$ & \\
\hline & Almajmaah & $1(6.30 \%)$ & $1(14.3 \%)$ & \\
\hline & AlBusera & $2(12.5 \%)$ & $0(0.0 \%)$ & \\
\hline & Alhamra & $4(25.0 \%)$ & $0(0.0 \%)$ & \\
\hline \multirow{4}{*}{ Age (years) } & $35-39$ & $5(31.3 \%)$ & $2(28.6 \%)$ & \multirow{4}{*}{0.784} \\
\hline & $40-44$ & $4(25 \%)$ & $3(42.9 \%)$ & \\
\hline & $45-49$ & $2(12.5 \%)$ & $1(14.3 \%)$ & \\
\hline & $>50$ & $5(31.3 \%)$ & $1(14.3 \%)$ & \\
\hline \multirow{3}{*}{ Qualification } & Masters & $0(0.0 \%)$ & $0(0.0 \%)$ & \multirow{3}{*}{$0.022^{*}$} \\
\hline & MBBS & $15(93.8 \%)$ & $3(42.9 \%)$ & \\
\hline & Diploma & $1(6.30 \%)$ & $3(42.9 \%)$ & \\
\hline \multirow{3}{*}{ Experience Specialty } & $4-6$ years & $1(6.3 \%)$ & $0(0.0 \%)$ & \multirow{3}{*}{0.435} \\
\hline & $7-10$ years & $7(43.8 \%)$ & $5(71.4 \%)$ & \\
\hline & More than 10 years & $8(50 \%)$ & $2(28.6 \%)$ & \\
\hline \multirow{2}{*}{ Specialty } & General Practitioner & $14(87.5 \%)$ & $7(100 \%)$ & \multirow{2}{*}{0.328} \\
\hline & Resident & $2(12.5 \%)$ & $0(0.0 \%)$ & \\
\hline & $\begin{array}{l}\text { le 4. Association be } \\
\text { and Socio-Demogr }\end{array}$ & $\begin{array}{l}\text { etween } A D A \\
\operatorname{aphics}(N=\end{array}$ & $\begin{array}{l}\text { Attitude } \\
\text { 23) }\end{array}$ & \\
\hline
\end{tabular}

The overall mean AD score of 8 items was $3.08 \pm 0.34$. The mean score of $\mathrm{AD}$ was then categorized into as having a positive and negative attitude. Majority of the PHCP's had negative attitude $16(69.57 \%)$ and 7 (30.43\%) had positive attitude (Figure 2). The result of one-sample chi-square test 
showed that the overall attitude of PHCP's was inappropriate $\left(X^{2}=7.05(1), P=0.016\right)$.

The positive and negative attitude when compared with the demographic variables showed no significant association, age $(\mathrm{P}=0.784)$, gender $(\mathrm{P}=0.554)$, working $\mathrm{PHC}(\mathrm{P}=0.193)$, specialty $(\mathrm{P}=0.328)$ and experience in specialty $(\mathrm{P}=0.435)$.
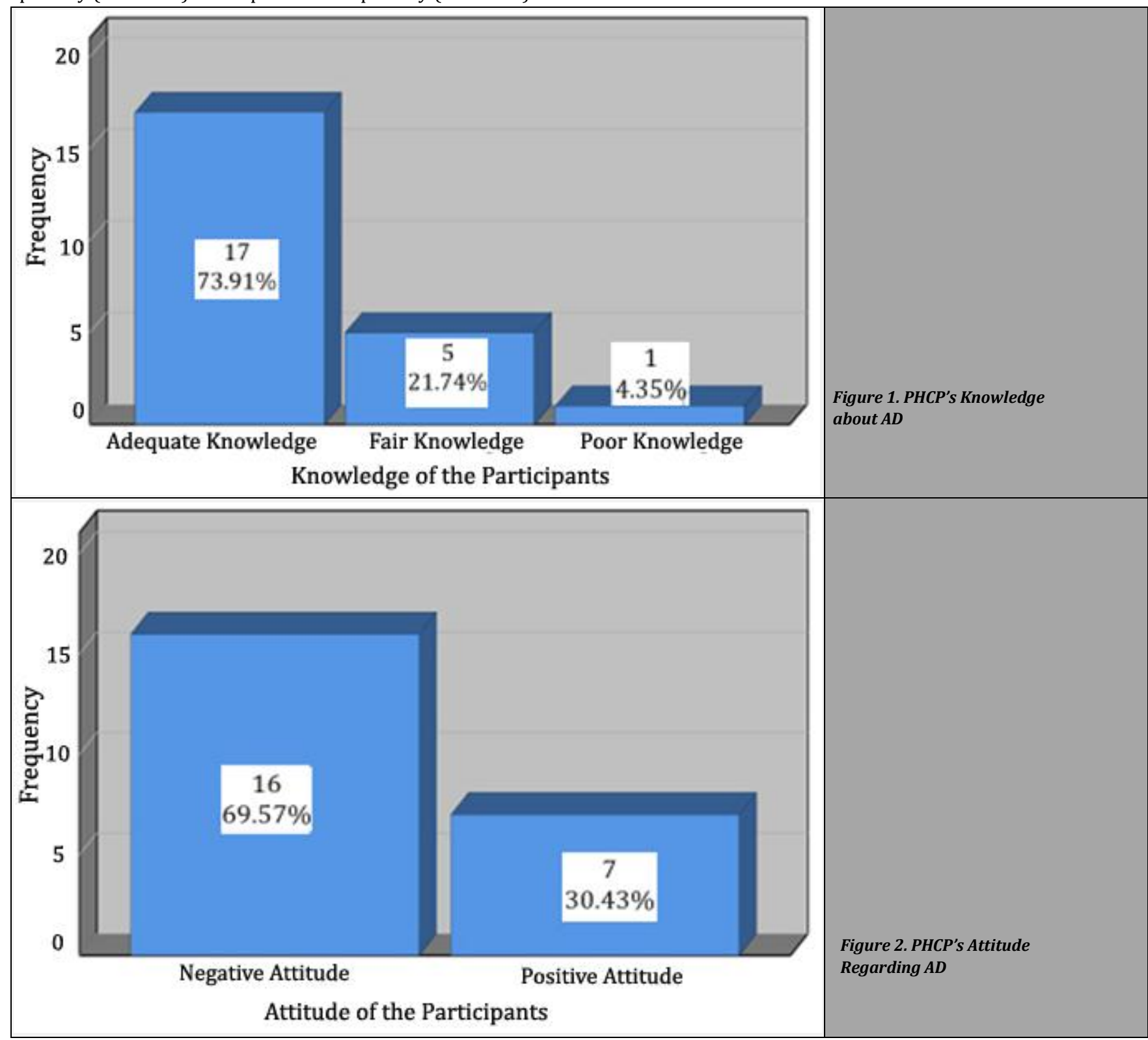

Whereas qualification and attitude were significantly associated $(\mathrm{P}=0.022)$ showing that those with MBBS qualification had significantly negative attitude towards AD. Results are presented in Table 4. about $A D$
Figure 1. PHCP's Knowledge

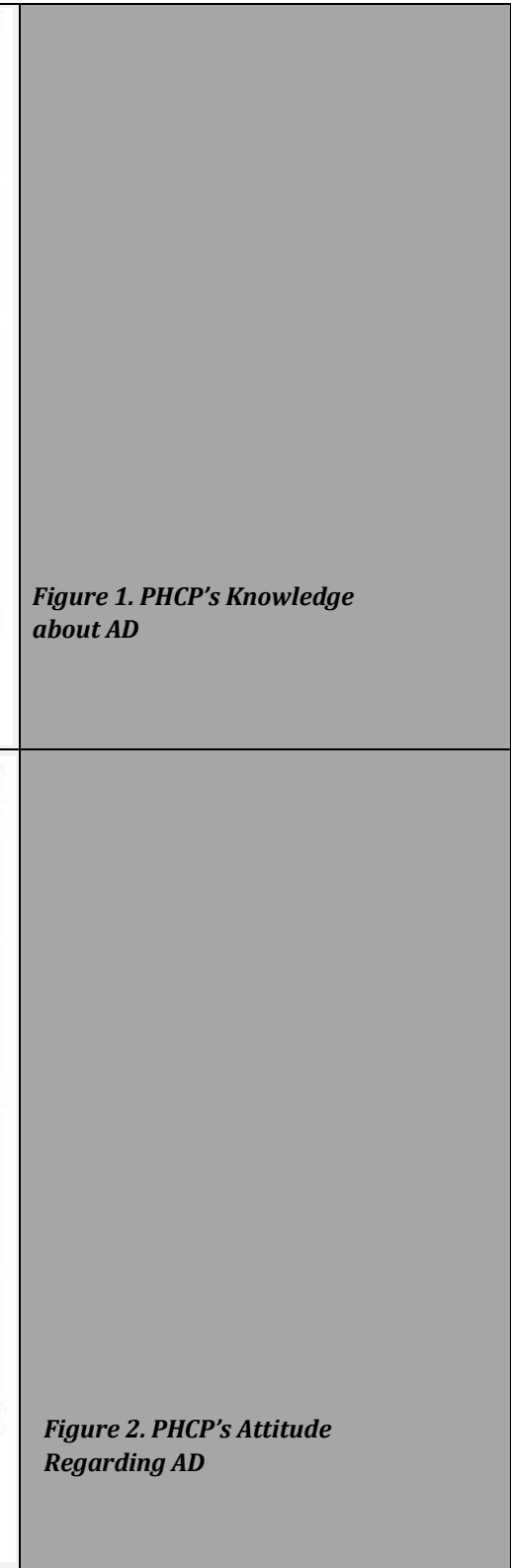

\section{DISCUSSION}

This study was designed to assess the level of knowledge and attitude of PHC practitioners about Atopic Dermatitis. All Primary Health Care Providers (PHCPs) working in Majmaah, Saudi Arabia were included in the study.

Most of the participants correctly identified the cause of AD (91.3\%). This was higher than what was reported by Kouotou EA et al. who reported that $64 \%$ of the respondents reported allergy as a cause of $\mathrm{AD}$ while $43 \%$ stated that genetic causes were also responsible for the disease, the psychological cause was rarely mentioned in his study. ${ }^{21}$ In our study, most of the PHC physicians were familiar with diagnostic criteria of atopic dermatitis. This was consistent with results of a study conducted in Southeast Asian dermatologists in Singapore, Malaysia, Thailand, Taiwan, and Hong Kong in the management of atopic dermatitis. ${ }^{22}$

Results showed that $73.9 \%$ of the primary health care physicians in Majmaah had adequate $\mathrm{AD}$ knowledge. This finding was higher than the level of knowledge reported among PHCPs in Jeddah, Saudi Arabia which found an average level of knowledge between $41.1 \%$ and $55.2 \%$ in the domains of self-assessment, overall knowledge, and management of AD. In a study conducted in Cameron, PHC practitioners had poor to average knowledge about AD. 21

In our results no relation was found between Level of AD knowledge and gender, age, qualifications, specialty, or experience in specialty. Studies conducted in Saudi Arabia found a significant relationship between AD knowledge and gender with females having better knowledge than males. ${ }^{20,21}$ Almaliki RA et al. found a statistical significance between AD 
knowledge and the age of respondents. ${ }^{20}$ A study conducted elsewhere found relation between $\mathrm{AD}$ knowledge and specialty. ${ }^{20}$

Our results found that the attitude of PHCPs towards AD was appropriate; This was in consistent with a study conducted by Kouotou EA et al. who found that most of the PHCPs had poor attitude towards the disease. ${ }^{21}$ The author attributed poor attitude to the inadequate knowledge and poor practice towards the disease.

\section{CONCLUSIONS}

The level of knowledge of PHCPs in Majmaah, Saudi Arabia, with regard to atopic dermatitis was found to be adequate, whereas, the attitude was observed to be negative. Focusgroup discussions, tailored sessions, or continuous medical education programs can be conducted to discuss the management guidelines on this condition with the PHCP's. Special training and continuous supervision are recommended to improve the attitude of the PHCPs towards the disease.

Data sharing statement provided by the authors is available with the full text of this article at jemds.com.

Financial or other competing interests: Author received Grants from The author extends his appreciation to the Deanship of Scientific Research at Majmaah University for funding this work under project number (R-2021-168).

Disclosure forms provided by the authors are available with the full text of this article at jemds.com.

\section{REFERENCES}

[1] Brown SJ. Atopic eczema. Clin Med (Lond) 2016;16(1):669.

[2] Deckers IAG, McLean S, Linssen S, et al. Investigating international time trends in the incidence and prevalence of atopic eczema 1990-2010: a systematic review of epidemiological studies. PLoS One 2012;7(7):e39803.

[3] Weidinger S, Beck LA, Bieber T, et al. Atopic dermatitis. Nat Rev Dis Primers 2018;4(1):1.

[4] Asher MI, Montefort S, Björkstén B, et al. Worldwide time trends in the prevalence of symptoms of asthma, allergic rhino conjunctivitis, and eczema in childhood: ISAAC phases one and three repeat multicounty cross-sectional surveys. Lancet 2006;368(9537):733-43.

[5] Smith SD, Lee A, Blaszczynski A, et al. Pharmacists' knowledge about use of topical corticosteroids in atopic dermatitis: pre and post continuing professional development education. Australas J Dermatol 2016;57(3):199-204.

[6] Mahnashi T, Haddadi Y, Yassin A. Epidemiology of atopic dermatitis among children in Jazan Region, Saudi Arabia. Epidemiology 2017;3(7):1-6.

[7] Mohn CH, Blix HS, Halvorsen JA, et al. Incidence trends of atopic dermatitis in infancy and early childhood in a nationwide prescription registry study in Norway. JAMA Netw Open 2018;1(7):e184145.
[8] Thomsen SF. Atopic dermatitis: natural history, diagnosis and treatment. ISRN Allergy 2014;2014.

[9] Alqadheb AFA, Alsharif ZMU, Alghamdi AMH, et al. Prevalence of atopic dermatitis among children in Jeddah, Saudi Arabia (2013-2014). Int J Dermatol Cosmetic Sci 2015;1(1):8-11.

[10] Jeziorkowska R, Rożalski M, Skowroński K, et al. Can evaluation of specific immunoglobulin $\mathrm{E}$ serum concentrations of antibodies to aeroallergens in atopic dermatitis patients replace skin prick tests method in clinical practice? Postepy Dermatol Alergol 2019;36(4):478-84.

[11] Eichenfield LF, Tom WL, Chamlin SL, et al. Guidelines of care for the management of atopic dermatitis: section 1 . Diagnosis and assessment of atopic dermatitis. J Am Acad Dermatol 2014;70(2):338-51.

[12] Berke R, Singh A, Guralnick M. Atopic dermatitis: an overview. Am Fam Physician 2012;86(1):35-42.

[13] Alqahtani JM. Atopy and allergic diseases among Saudi young adults: a cross-sectional study. J Int Med Res 2020;48(1):1-11.

[14] Alhazmi M, Basudan A, Moafa A, et al. Epidemiology of atopic dermatitis among children in Jazan Region, Saudi Arabia. International Journal of Medical and Health Research 2017;3(7):41-5.

[15] Alkatheri AA. Knowledge of common dermatological disorders among primary health care physicians in Jeddah in the kingdom of Saudi Arabia in 2014. IJCMPR 2017;3(05):1724-8.

[16] Al-Zahrani MAA, Nahar S, Abdullah Al-Zahrani SA, et al. Knowledge, attitude and practice of primary care physicians regarding common dermatological disorders in Abha City, Kingdom of Saudi Arabia. IOSR Journal of Pharmacy 2017;7(2):89-110.

[17] Alotaibi AA, Baradah RK, Alzahrani AJ. Knowledge and practice of primary health care physicians for management of acne vulgaris in Sudair area, Saudi Arabia, 2017-2018. International Journal of Medical and Health Research 4(9):8-11.

[18] Schofield JK, Fleming D, Grindlay D, et al. Skin conditions are the commonest new reason people present to general practitioners in England and Wales. Br J Dermatol 2011;165(5):1044-50.

[19] Patro BK, Tripathy JP, De D, et al. Diagnostic agreement between a primary care physician and a tele dermatologist for common dermatological conditions in North India. Indian Dermatol Online J 2015;6(1):21-6.

[20] Cowdell F, Ahmed T, Layfield C. Knowledge mobilization: a UK co-creation study to devise strategies to amend lay and practitioner atopic eczema mind lines to improve consultation experiences and self-management practices in primary care. BMJ Open 2020;10(9):e036520.

[21] Kouotou EA, Nansseu JRN, Engome ADN, et al. Knowledge, attitudes and practices of the medical personnel regarding atopic dermatitis in Yaoundé, Cameroon. BMC Dermatol 2017;17(1):1.

[22] Ee S, Tay YK, Chu CY, et al. A study on the knowledge, attitudes and practices of Asian dermatologists in the management of atopic dermatitis. Dermatologica Sinica 2020;38(2):67-80. 